Journal of Patient-Centered

\title{
Multiple Myeloma Baseline Immunoglobulin G Level and Pneumococcal Vaccination Antibody Response
}

\author{
Michael A. Thompson \\ Martin K. Oaks \\ Maharaj Singh \\ Karen M. Michel \\ Michael P. Mullane \\ Husam S. Tarawneh \\ Angi Kraut \\ Kayla J. Hamm
}

Follow this and additional works at: https://aah.org/jpcrr

Part of the Immune System Diseases Commons, Medical Immunology Commons, Neoplasms

Commons, Oncology Commons, Public Health Education and Promotion Commons, and the Respiratory

Tract Diseases Commons

\section{Recommended Citation}

Thompson MA, Oaks MK, Singh M, Michel KM, Mullane MP, Tarawneh HS, Kraut A, Hamm KJ. Multiple myeloma baseline immunoglobulin $\mathrm{G}$ level and pneumococcal vaccination antibody response. J Patient Cent Res Rev. 2017;4:131-5. doi: 10.17294/2330-0698.1453

Published quarterly by Midwest-based health system Advocate Aurora Health and indexed in PubMed Central, the Journal of Patient-Centered Research and Reviews (JPCRR) is an open access, peer-reviewed medical journal focused on disseminating scholarly works devoted to improving patient-centered care practices, health outcomes, and the patient experience. 


\title{
Multiple Myeloma Baseline Immunoglobulin G Level and Pneumococcal Vaccination Antibody Response
}

\author{
Michael A. Thompson, MD, PhD, ${ }^{1,3}$ Martin K. Oaks, $\mathrm{PhD},{ }^{2}$ Maharaj Singh, $\mathrm{PhD},{ }^{1}$ Karen M. Michel, BS, ${ }^{1}$ \\ Michael P. Mullane,${ }^{3}$ MD, Husam S. Tarawneh, MD, ${ }^{3}$ Angi Kraut, RN, BSN, OCN, ${ }^{1}$ Kayla J. Hamm, BSN ${ }^{3}$ \\ ${ }^{1}$ Aurora Research Institute, Aurora Health Care, Milwaukee, WI; ${ }^{2}$ Transplant Research Laboratory, Aurora St. Luke's \\ Medical Center, Aurora Health Care, Milwaukee, WI; ${ }^{3}$ Aurora Cancer Care, Aurora Health Care, Milwaukee, WI
}

\begin{abstract}
Infections are a major cause of morbidity and mortality in multiple myeloma (MM), a cancer of the immune system. Vaccination clinical efficacy endpoints have not been demonstrated, and there are limited data on surrogate markers of efficacy. This pilot study evaluated sequential immunologic markers after standard pneumococcal vaccination (PV) in patients with $\mathrm{MM}$ and non-MM controls. Vaccination was standard for PV (PCV13 or PPV23), with laboratory testing at baseline and at 2, 4, 12 and 24 weeks after vaccination. Immunoglobulin $\mathrm{G}(\mathrm{IgG})$ antibodies to pneumococcal antigens were detected by ELISA. Prevaccination total IgG levels and IgG subclass levels were also measured by ELISA. Four of 6 controls responded with at least a 2-fold increase in antibody concentration; only 2 controls had a sustained increase in concentration. Six of 8 patients with MM had at least a 2-fold antibody increase; however, only 2 of these patients showed a sustained increase of antipneumococcal antibody. Response rate differences were not statistically significant in this small pilot, and there was no relationship between responsiveness to PV and initial serum total lgG levels or lgG subclasses at study entry. Future prospective studies are needed to ascertain the immunological and clinical efficacy and effectiveness of various vaccines and vaccination strategies in MM. (J Patient Cent Res Rev. 2017;4:131-135.)
\end{abstract}

Keywords multiple myeloma, vaccination, pneumococcal, clinical efficacy, immunology, antibody, immunoglobulin $G$

$\mathrm{M}$ ultiple myeloma (MM) is a cancer of the immune system. Despite the development of improved therapies for MM, infection is a major cause of morbidity and a leading cause of death. Patients with MM have a nearly 8-fold increased risk of pneumonia, ${ }^{1}$ and a recent report by Teh and colleagues revealed that over one-third of patients with MM had confirmed blood stream infections. ${ }^{2}$ Induction therapy was associated with gram-positive pathogens, while MM patients with progressive disease had more gram-negative pathogens. Risk factors for serious blood stream infections included progressive disease and recent autologous stem cell transplantation.

Tete and colleagues noted that the immunosuppression in $\mathrm{MM}$ is confounded by patient age and drug effect in

Correspondence: Michael A. Thompson, MD, PhD,

Aurora Research Institute, 960 N. 12th Street, \#4111,

Milwaukee, WI, 53233, T: +1-414-219-4763,

Email: Michael.A.Thompson@aurora.org addition to the underlying cancer. ${ }^{3} \mathrm{~A}$ previous review of literature on vaccinations in $\mathrm{MM}^{4}$ determined that while vaccinations are recommended in $\mathrm{MM}$, clinical efficacy endpoints have not been demonstrated and surrogate markers of efficacy have limited data. Antibody response of a doubling in immunoglobulin $\mathrm{G}$ ( $\mathrm{IgG}$ ) and immunoglobulin $\mathrm{M}$ antibody titers has been historically used as a metric of response, but in general this has not been clinically validated. ${ }^{5}$

Many clinicians may not comply with recommendations for pneumococcal pneumonia vaccination (PV) because of a perception that MM and other cancers of the immune system inherently are accompanied by immunologic compromise, especially in the setting of reduced IgG levels. We hypothesized that total IgG levels and levels of IgG subclasses might predict responsiveness to PV. To that end, we evaluated prevaccination total $\mathrm{IgG}$ levels and IgG subclasses and monitored IgG responses to pneumococcal antigens in a small cohort of MM patients and healthy controls. 
Discovering that neither total IgG levels nor individual IgG subclass levels were predictive of responsiveness to PV, we surmise that levels of IgG cannot be used to predict responsiveness to $\mathrm{PV}$ and that significant immune responsiveness to pneumococcal antigens remains intact in many patients with MM.

\section{METHODS}

Patients with MM and non-MM control participants signed informed consent to this institutional review board-approved study. By inclusion criteria, all participants recruited were greater than 50 years of age. MM included a clinical diagnosis of smoldering MM or symptomatic MM. The patients with MM were not selected based on therapeutic regimen or disease status. Vaccination choice was based on patient and physician discussion and not a standardized protocol (as is the case after autologous stem cell transplantation).

The first participant was accrued on December 30, 2014, and the last on January 28, 2016. The last follow-up date was July 12, 2016. PV used was either 13-valent pneumococcal conjugate vaccine (PCV13) or 23-valent pneumococcal polysaccharide vaccine (PPV23). Research laboratory testing was performed at baseline and at 2, 4, 12 and 24 weeks after vaccination.

A vaccination pattern of PCV13 first followed by PPV23 suggested at $\geq 26$ weeks (falling outside of research testing window of 24 weeks) was preferred. IgG antibodies to tetanus toxoid were detected by ELISA, as previously described. ${ }^{6}$

Antipneumococcal IgG levels were determined with the VaccZyme ${ }^{\mathrm{TM}}$ anti-PCP IgG enzyme immunoassay kit (MK012-U, The Binding Site Group Ltd, Birmingham, United Kingdom) according to the manufacturer's instructions. Total $\mathrm{IgG}$ and $\mathrm{IgG}$ subclasses were measured with ELISA kits (E80-104 and 991000) from Bethyl Laboratories, Inc. (Montgomery, TX) and Thermo Fisher Scientific Inc. (Waltham, MA), respectively. Identity of the respective samples was blinded to the staff that performed the assay.

\section{RESULTS}

Fourteen study participants -8 with MM (5 male, 3 female) and 6 controls ( 3 male, 3 female) - were enrolled. Median age for patients with MM was 68.1 years (range: 58-77) and for controls was 64.2 years (range: 60-72).
The humoral response to immunization with PV varied considerably for both MM patients and controls (Figure 1 and Table 1). Although 4 of 6 controls responded with at least a 2 -fold increase in antibody concentration, only 2 showed a sustained increase in concentration at the closing visit. Six of $8 \mathrm{MM}$ patients showed at least a 2-fold increase in antibody levels at some point during the course of the study. Like the control group, only $2 \mathrm{MM}$ patients showed a sustained increase of antipneumococcal IgG levels. The difference in response rates did not, however, reach statistical significance.

Antibody levels to tetanus toxoid were determined to assure that changes in pneumococcal antibody levels were not due to global changes in IgG levels in the absence of immunization. Of 14 study subjects, 3 showed a transient increase in tetanus toxoid titers (2 MM, 1 control), and none showed more than a 2-fold increase during the course of the study (Figure 2). None of the subjects received vaccination with tetanus toxoid during the course of the study.

To examine whether a relationship existed between total $\mathrm{IgG}$ and $\mathrm{IgG}$ subclasses levels at the time of entry into the study (prevaccination) and response to vaccination, we grouped the data into responders and nonresponders based on the presence or absence of at least a 2-fold change in antibody concentration during the course of the study. The data showed no significant relationship between prior total $\mathrm{IgG}$ levels, nor individual $\mathrm{IgG}$ subclasses, and responsiveness to either type of vaccination (Table 2 and Figure 3). The vast majority of control subjects in our study had $\operatorname{IgG}$ levels that were within previously published reference ranges for healthy adults. ${ }^{7}$

\section{DISCUSSION}

In this pilot study, we found no relationship of PV antibody response with total IgG level at the time of vaccination. This is consistent with findings by Beers et al that $\mathrm{IgG}$ isotypes may be of more importance than the total IgG level. ${ }^{8}$ Consistent with our pilot findings, Karlsson and colleagues showed that total IgG antibody response does not correlate with functional assays of pneumococcal killing. ${ }^{5}$ Thus, from this limited data, it appears that clinicians should not rely on quantitation of IgGs nor their subclasses when deciding whether or not to vaccinate patients with MM. 


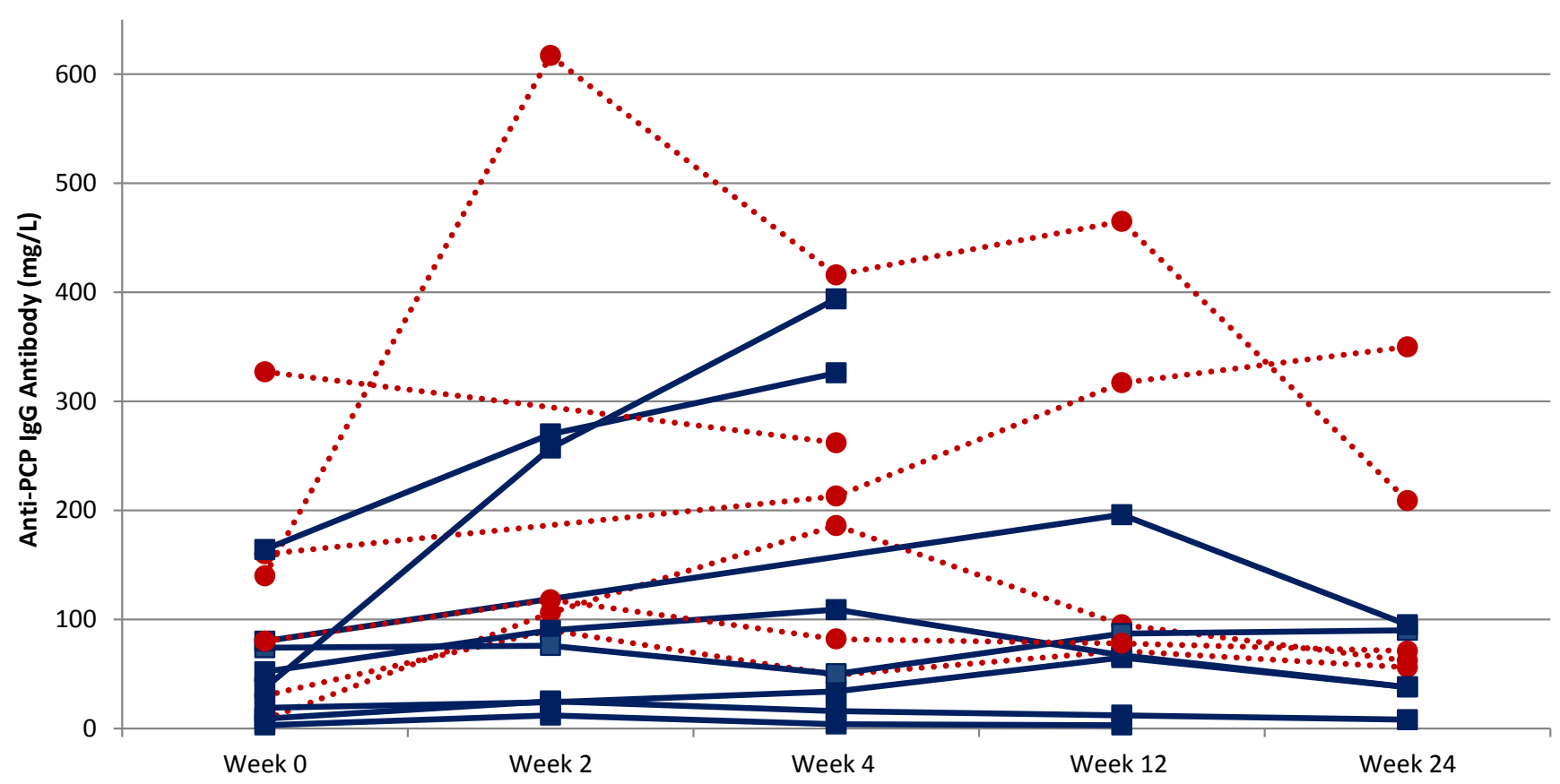

Figure 1. Antibody responses to pneumococcal vaccination. Controls = dotted lines; patients = solid lines. Values represent mean titer of duplicate measurements.

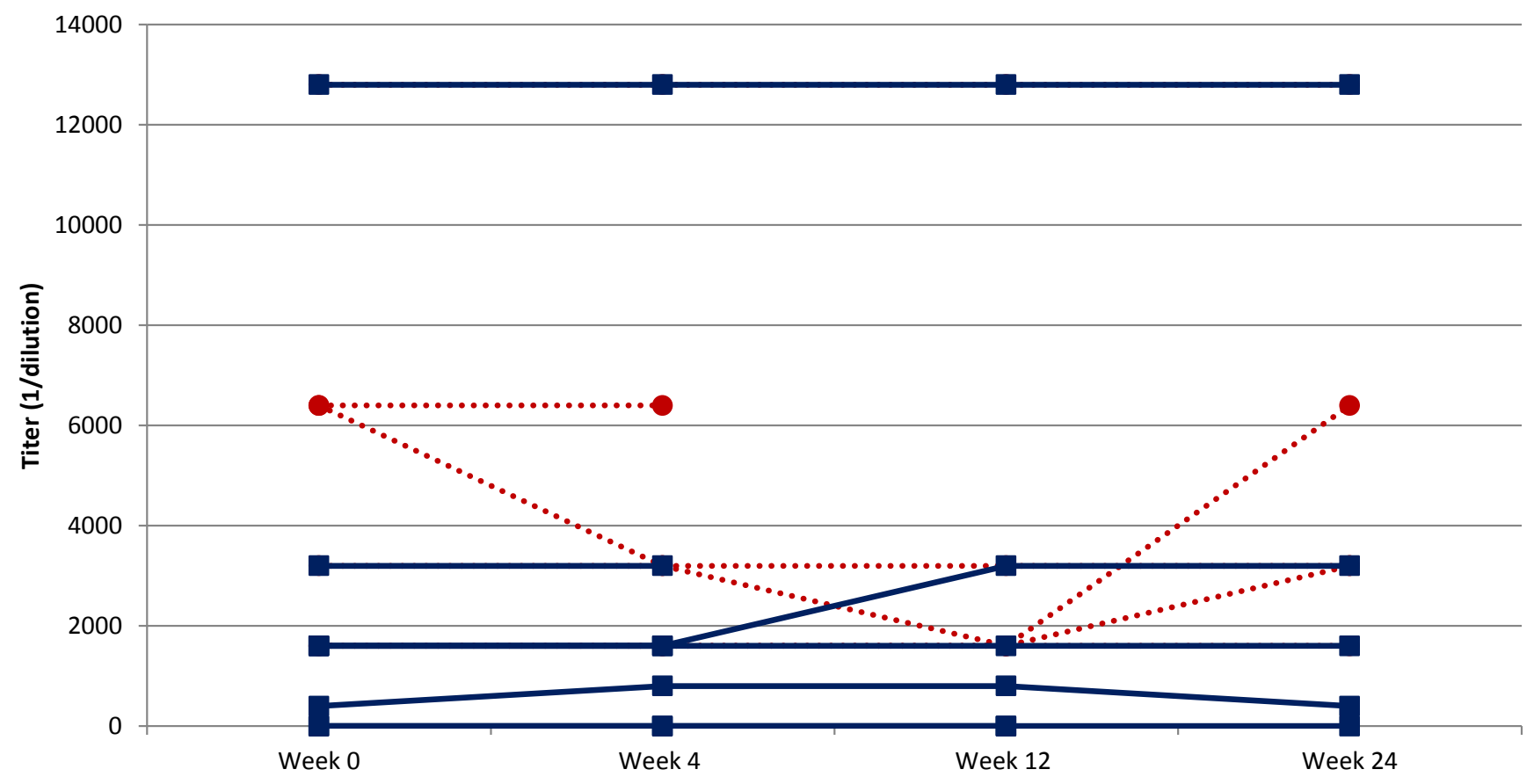

Figure 2. Antibody levels to tetanus toxoid. Controls = dotted lines; patients = solid lines. Values represent mean titer of duplicate measurements. Note that no subjects received vaccination with tetanus toxoid during the course of the study. 
Table 1. Responses to Pneumococcal Vaccination

\begin{tabular}{lllll}
\hline Change in antibody titer & All subjects & Controls & Patients & $\boldsymbol{P}$ \\
\hline Twofold increase at any time point & $10 / 14(71 \%)$ & $4 / 6(67 \%)$ & $6 / 8(75 \%)$ & $>0.999$ \\
Twofold increase at last study visit & $4 / 14(29 \%)$ & $2 / 6(33 \%)$ & $2 / 8(25 \%)$ & $>0.999$ \\
\hline
\end{tabular}

Data are expressed as fraction of subjects who achieved at least a 2-fold increase in antibody titer at any point in the study or at the last study visit.

$P$-values were obtained with the use of the Fisher's exact statistic.

Table 2. Levels of Total Immunoglobulin G $(\lg G)$ and $\lg G$ Subclasses at Study Entry

\begin{tabular}{|c|c|c|c|c|}
\hline IgG level & Controls & Patients & $P^{a}$ & $P^{b}$ \\
\hline $\begin{array}{l}\text { Mean total IgG (SD) } \\
\text { Range of total IgG }\end{array}$ & $\begin{array}{c}1,096 \mathrm{mg} / \mathrm{dL}(610) \\
510-2,004\end{array}$ & $\begin{array}{c}1,195 \mathrm{mg} / \mathrm{dL}(1,519) \\
189-4,583\end{array}$ & 0.3660 & 0.8830 \\
\hline $\begin{array}{l}\text { Mean total } \operatorname{lgG}^{1}(S D) \\
\text { Range of total } \operatorname{lgG}^{1}\end{array}$ & $\begin{array}{c}1,373 \mathrm{mg} / \mathrm{dL}(501) \\
1,007-2,119\end{array}$ & $\begin{array}{c}3,326 \mathrm{mg} / \mathrm{dL}(4,706) \\
516-14,276\end{array}$ & 0.7960 & 0.3360 \\
\hline $\begin{array}{l}\text { Mean total } \operatorname{lgG}^{2}(S D) \\
\text { Range of total } \operatorname{lgG}^{2}\end{array}$ & $\begin{array}{c}426 \mathrm{mg} / \mathrm{dL}(374) \\
125-1,103\end{array}$ & $\begin{array}{c}166 \mathrm{mg} / \mathrm{dL}(107) \\
14-342\end{array}$ & 0.0930 & 0.1540 \\
\hline $\begin{array}{l}\text { Mean total } \operatorname{lgG}^{3}(S D) \\
\text { Range of total } \operatorname{lgG}^{3}\end{array}$ & $\begin{array}{c}214 \mathrm{mg} / \mathrm{dL}(224) \\
78-644\end{array}$ & $\begin{array}{c}117 \mathrm{mg} / \mathrm{dL}(102) \\
11-272\end{array}$ & 0.1210 & 0.2960 \\
\hline $\begin{array}{l}\text { Mean total } \operatorname{lgG}^{4}(S D) \\
\text { Range of total } \lg ^{4} G^{4}\end{array}$ & $\begin{array}{c}86 \mathrm{mg} / \mathrm{dL}(101) \\
5-243\end{array}$ & $\begin{array}{c}26 \mathrm{mg} / \mathrm{dL}(34) \\
3-84\end{array}$ & 0.1210 & 0.2170 \\
\hline
\end{tabular}

Data are expressed as mean and standard deviation (SD), and were obtained by duplicate measurements of each sample.

${ }^{a} P$-values from median-test statistic.

${ }^{b} P$-values from t-test statistic, nonparametric and parametric analyses, respectively.
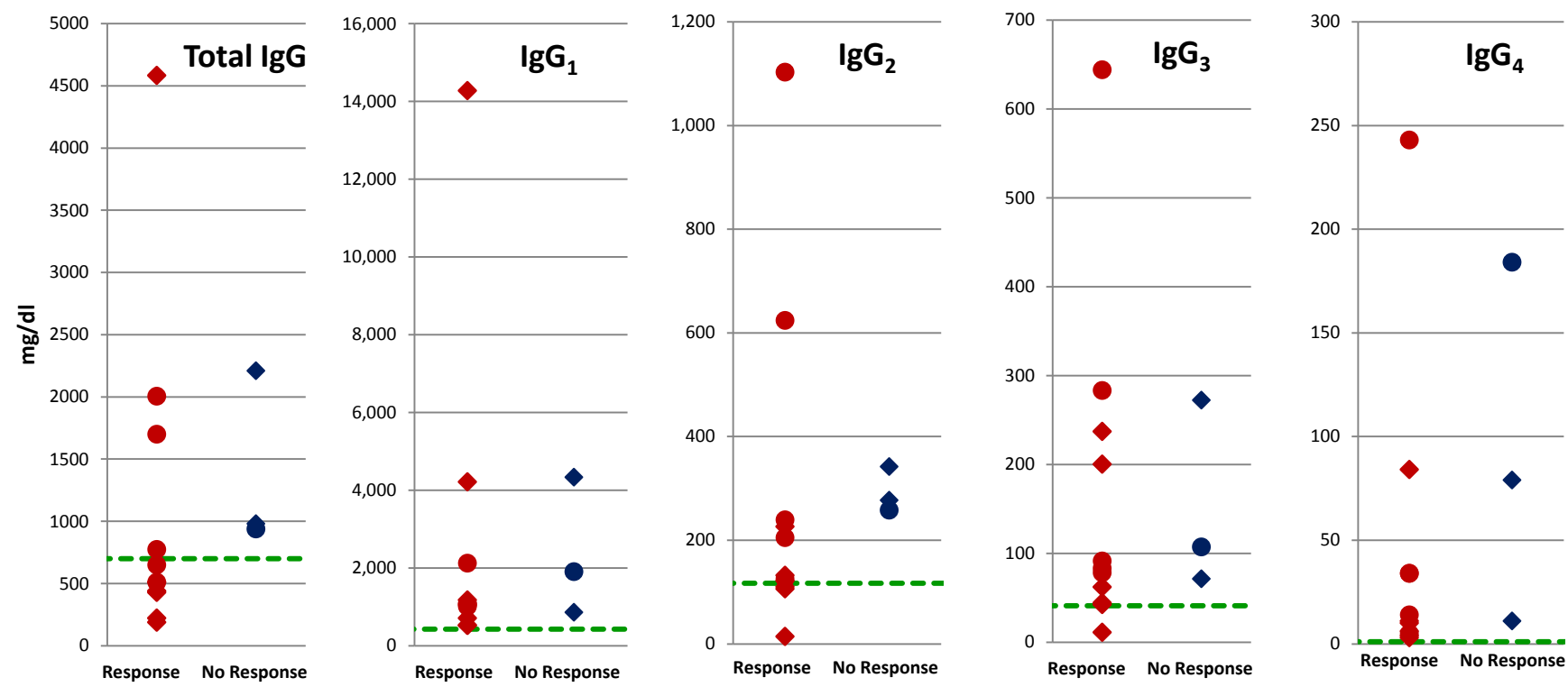

Figure 3. Total lgG and lgG subclass levels in patients with multiple myeloma prior to pneumococcal vaccination. Measurements obtained from duplicate determinations. Data are expressed as responders or nonresponders based on at least a 2-fold increase in titer at any time point during the study. The dashed line represents the low end of a reference range obtained from Medscape (http://emedicine.medscape.com/article/2157901-overview). Controls = circles; patients $=$ diamonds. 
Our study has several limitations, for example, small sample size, sample dropouts and a heterogeneous subject population. We are unaware of prior $\mathrm{MM}$ vaccination immunology response time courses. This may be because of the difficulties involved in studying PV that is administered by the recommended protocol of PCV13 followed by PPV23, and the potential prolonged follow-up that comes with it. In our study, a vaccination pattern of PCV13 first followed by PPV23 suggested at $\geq 26$ weeks was preferred, with antibody measurements occurring prior to any dose of PPV23. However, for clinical relevance, it may be necessary to measure after both PCV13 and PPV23 vaccines are administered. Other areas of potential increased risk to patients with MM include meningitis (hazard ratio: 16.6) and the role of the meningococcal vaccine. ${ }^{1}$ Haemophilus influenzae vaccination has been recommended, ${ }^{9}$ but to our knowledge only one abstract has evaluated response (in the post-stem cell transplant setting). ${ }^{10}$

Future vaccination studies should consider: 1) a homogeneous population - eg, therapy trial or autologous stem cell transplant - with standardized re-vaccination and sequential testing; 2) validating relevant immunologic surrogates (eg, antibody response twice baseline); 3 ) the correlation of metric with functional outcomes such as hospitalization, cost, and death; 4) a larger sample size with possible stratification by past or current treatment regimen; and 5) epidemiologic data that may complement biomarker response translational approaches.

Prospective studies are needed to ascertain the immunological and clinical efficacy and effectiveness of various vaccines and vaccination strategies in immunosuppressed patients.

\section{Conflicts of Interest}

Michael Thompson serves on the myeloma and indolent lymphoma committees of Via Oncology, LLC (Pittsburgh, PA); medical advisory board of AIM Specialty Health (Deerfield, IL); scientific steering committee for the Connect $^{\circledR}$ MDS/AML Registry (Celgene Corporation, Summit, NJ); and multiple myeloma registry of Takeda Oncology (Cambridge, MA).

\section{Funding Sources}

Funding for this study was provided by the Vince Lombardi Cancer Foundation as an Aurora Health Care Cancer Research Award.

\section{Patient-Friendly Recap}

- Infections are the leading cause of death in patients with multiple myeloma.

- Guidelines recommend pneumonia vaccinations, but benefit of the vaccine in myeloma patients is not proven.

- Although more research is needed, this pilot study suggested that a myeloma patient's baseline antibody level (ie, lgG) does not predict his or her subsequent response to pneumococcal vaccination.

- The role of vaccination in cancers of the immune cells is complicated and warrants investigation; for now, patients should receive vaccination as directed by their oncologist.

\section{References}

1. Blimark C, Holmberg E, Mellqvist UH, et al. Multiple myeloma and infections: a population-based study on 9253 multiple myeloma patients. Haematologica. 2015;100:107-13. CrossRef

2. Teh BW, Harrison SJ, Slavin MA, Worth LJ. Epidemiology of bloodstream infections in patients with myeloma receiving current era therapy. Eur J Haematol. 2017;98:149-53. CrossRef

3. Tete SM, Bijl M, Sahota SS, Bos NA. Immune defects in the risk of infection and response to vaccination in monoclonal gammopathy of undetermined significance and multiple myeloma. Front Immunol. 2014;5:257. CrossRef

4. Alemu A, Richards JO, Oaks MK, Thompson MA. Vaccination in multiple myeloma: review of current literature. Clin Lymphoma Myeloma Leuk. 2016;16:495-502. CrossRef

5. Karlsson J, Roalfe L, Hogevik H, et al. Poor correlation between pneumococcal $\operatorname{IgG}$ and $\operatorname{IgM}$ titers and opsonophagocytic activity in vaccinated patients with multiple myeloma and Waldenstrom's macroglobulinemia. Clin Vaccine Immunol. 2016;23:379-85. CrossRef

6. Oaks M, Taylor S, Shaffer J. Autoantibodies targeting tumorassociated antigens in metastatic cancer: sialylated IgGs as candidate anti-inflammatory antibodies. OncoImmunology. 2013;2:e24841. CrossRef

7. Buckley CE 3rd, Dorsey FC. Serum immunoglobulin levels throughout the life-span of healthy man. Ann Intern Med. 1971;75:673-82. CrossRef

8. Beers SA, Glennie MJ, White AL. Influence of immunoglobulin isotype on therapeutic antibody function. Blood. 2016;127:1097-101. CrossRef

9. Al-Farsi K. Multiple myeloma: an update. Oman Med J. 2013;28:3-11. CrossRef

10. Shah G, Palazzo M, Copelan O, et al. Re-immunization following autologous hematopoietic stem cell transplantation (auto HCT) is safe and effective in patients with multiple myeloma receiving lenalidomide maintenance. 16th International Myeloma Workshop Abstract Book. Fairfax, VA: Spargo Inc, 2017, p. e119.

(C) 2017 Aurora Health Care, Inc. 